\title{
GENETIC VARIATION OF ARCTIC STARFLOWR (TRIENTALIS EUROPAEA SUBSP. ARCTICA (FISCH. EX HOOK.) HULTÉN) (PRIMULACEAE), AN ENDANGERED HERB SPECIES OF SOUTH KOREA: IMPLICATIONS FOR CONSERVATION STRATEGIES
}

\author{
YEON, M. H. - LEE, S. H. - LEE, Y. E. - KIM, S. K.* \\ Department of Life Science, Chung-Ang University, 84 Heukseok-ro, Dongjak-gu, Seoul, Korea \\ *Corresponding author \\ e-mail: skkimbio@cau.ac.kr; phone: +82-2-820-5210; fax: +82-2-825-5206
}

(Received $17^{\text {th }}$ Jun 2021; accepted $3^{\text {rd }}$ Sep 2021)

\begin{abstract}
Trientalis europaea subsp. arctica (Primulaceae) is an herb species that is distributed widely across the northern hemisphere but is endangered in South Korea. In this study, we investigated the genetic diversity and structure of T. arctica populations by using Random Amplification Polymorphic DNA (RAPD) markers. Ten RAPD primers were used to amplify 81 loci from 9 populations consisting of 270 individuals. T. arctica shows high genetic diversity at the species level, but low genetic diversity at the population level. The percentage of polymorphic bands (PPB) was $86.4 \%$ at the species level, but the average PPB at the population level was 7.1\%. In addition, Nei's gene diversity (species level $=0.27$; population level $=0.02)$ and Shannon's information index ( indicated similar genetic structures. T. arctica showed a high degree of genetic differentiation $\left(\Phi_{s t}=0.96\right.$ and $G s t=0.911)$ between populations and limited gene flow $(\mathrm{Nm}=0.01)$. These results may be attributed to the fact that $T$. arctica is a refugial species in South Korea and to its long-term isolation in alpine regions. Considering the extremely low genetic diversity and high genetic differentiation of $T$. arctica populations, both in situ and ex situ conservation should be carried out actively for this species.
\end{abstract}

Keywords: genetic diversity, genetic differentiation, plant conservation, RAPD, northern plant

\section{Introduction}

The genus Trientalis belongs to the Primulaceae family and is composed of boreal herb species that are distributed in the understory of woodlands. Plants of this genus appear widely throughout Northern Europe, East Asia, and North America in the northern hemisphere, have creeping rhizomes, and undergo vegetative reproduction by extending sideways near the soil surface (Hiirsalmi, 1969; Kovanda, 1995; Piqueras and Klimes, 1998; Piqueras, 1999; Piqueras et al., 1999). Two species, T. europaea L. and T. europaea subsp. arctica (Fisch. ex Hook.) Hultén, grow naturally in South Korea (Lee, 2003, 2006). However, T. europaea has been rarely reported in domestic research on flora and plant distribution, whereas almost all data report the distribution of T. arctica (Song et al., 2009; Shin et al., 2010; Park et al., 2011; Kim et al., 2012, 2015, 2017; Park and Kim, 2012; Li et al., 2014; Yoon et al., 2015; Sung et al., 2018) therefore, most Trientalis species in South Korea are considered to be T. arctica.

In South Korea, the distribution of T. arctica is limited to the alpine and sub-alpine regions of the Baekdu-daegan area in the north-south Korean Peninsular region. The Baekdu-daegan region on the Korean Peninsula is believed to have served as a major refugia for northern plants during the Quaternary Period (Chung et al., 2012, 2013, 2014; Lee et al., 2016). Therefore, the current distribution of $T$. arctica, a northern plant, is expected to have been greatly affected by climate change from the ice age to the present. During the ice age, the distribution of northern plants expanded to the south due to 
reduced temperatures; subsequently, these plants either retreated to the north or changed their habitats to the alpine regions, which had lower temperatures than the other areas after the interglacial period. Plants left in the alpine regions were blocked in by temperature barriers and isolated, and form the current distribution of plants with ecological characteristics similar to those of $T$. arctica in these alpine regions. Since T. arctica is threatened by its limited distribution and population decline through indiscriminate harvesting and habitat damage, it has been designated as an endangered wildlife class II species by the Ministry of Environment, South Korea. It is also designated as a vulnerable species (VU), an endangered species category on the Korean Red List (Korea National Arboretum, 2009).

Genetic variation is considered an important factor in determining the survival of a species in a changing environment and is a fundamental component of biodiversity (Pauls et al., 2013). In particular, the maintenance of genetic diversity is a major concern for conservation biologists involved in the conservation and management of endangered species with small numbers or a limited distribution. To establish an appropriate conservation strategy for endangered or rare species, knowledge on the level of genetic variation within and between populations is essential basic information (Jiménez et al., 2002; Jeong et al., 2010; Wang et al., 2012). However, despite the importance of research on the genetic variations of $T$. arctica in ensuring the protection and proper management of this species, few studies have evaluated this topic.

Molecular markers have been used to measure genetic diversity and to study the genetic structure of plants within populations. Among them, random amplification polymorphic DNA (RAPD) markers are DNA-based dominant markers (Williams et al., 1990). Since they are dominant markers, they cannot easily distinguish between homozygotes and heterozygotes, and may exhibit low reproducibility. Nevertheless, these markers have been frequently used in studies on genetic variation because they offer advantages such as random sampling of the genome, high polymorphism, and low cost, and the fact that they do not require genomic information of the target species (Singh et al., 2012). In addition, since analysis using these markers requires only a small amount of sample, it is suitable for research on endangered or rare species.

In this study, we attempted to determine the level and structure of genetic variation in nine natural populations of $T$. arctica, an endangered species in South Korea, by using RAPD markers. Our main goals were as follows: (1) to measure genetic diversity at the species and population levels, (2) to understand the genetic differentiation pattern and genetic structure between populations, and (3) to interpret our results to an effective conservation strategy.

\section{Materials and methods}

\section{Study species and sampling}

According to a previous study, T. arctica is a clonal plant that reproduces through rhizomes, has very low seed production and seedling settlement, and is believed to have physiological and ecological characteristics almost similar to those of $T$. europaea (Tikhodeyev, 2003). During its vegetative pseudo-annual life cycle, the mother ramet dies after producing several daughter ramets during the growing season. These daughter ramets remain dormant in the ground, before growing and continuing the cycle during the next growing period (Piqueras et al., 1999). Five to ten leaves are gathered on the upper part of the stem and their edges are flat. One or two white whole flowers hang at the end 
of the peduncle from the end of the stem, and they are deeply divided into seven petals. The seven calyx leaves are narrow and lanceolate, have a pointed end, are split deeply, and spread horizontally. Fruits mature in September and are spherical capsules with a diameter of 2.5 to $3 \mathrm{~mm}$ (National Institute of Biological Resources, https://species.nibr.go.kr/, Fig. 1).
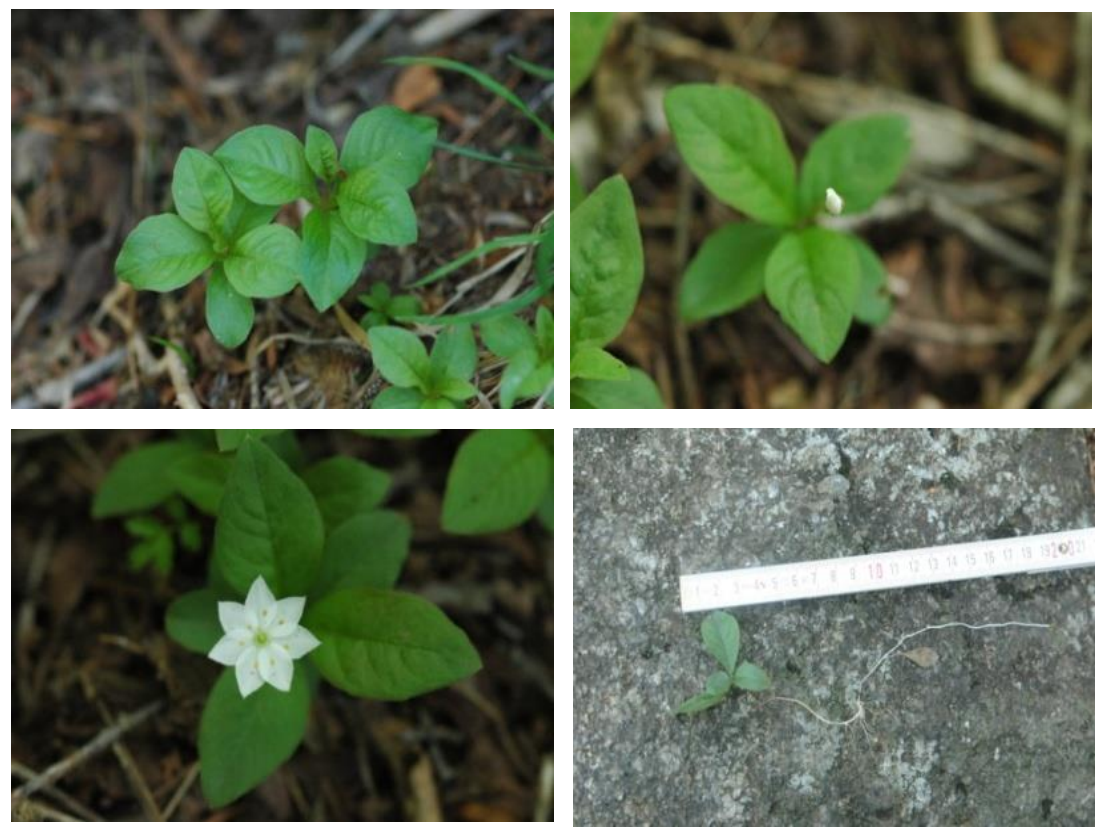

Figure 1. Morphological features of T. arctica in South Korea

In South Korea, T. arctica is mainly distributed on the northern slopes at an altitude of more than 1,000 m (Table 1, Fig. 2). It is known to be distributed in five areas, including Yongneup, Mount (Mt.) Seorak, Mt. Gaya, and Mt. Jiri. Among these, Yongneup, the northernmost area, is an alpine wetland located around the summit of Mt. Daeam. The Yongneup population inhabits the peat moss layer on the wetland floor and occupies a more heterogeneous habitat than the other populations, which live in the herbaceous layers of forests. The Mt. Seorak population is divided into three subpopulations (SA1, SA2, and SA3) according to the peaks inhabited, which are several kilometers apart from each other, and show no continuous distribution. The Mt. Taebaek population is divided into two subpopulations, TB1 and TB2. The TB1 population inhabits the moss layer on the rocky area of the ridge, and the TB2 population lives in the lower herbaceous layer of the coniferous forest near the peak. The Mt. Gaya population inhabits the herbaceous layer on the mountain ridge and the moss layer above the rock. The Mt. Jiri population is divided into two subpopulations (JR1, JR2) that occupy the herbaceous layer on the northwestern slope of the ridge.

A total of 270 T. arctica samples were collected from nine natural populations in South Korea, with 30 samples collected per population. Sample collection within each population was conducted with consideration to the topography of the area and was carried out at certain intervals between individuals to minimize their genetic relationship. The samples were collected in a paper bag, placed in a plastic container along with a moisture absorbent, and moved to the laboratory. Plant samples were stored at $-20{ }^{\circ} \mathrm{C}$ until DNA extraction. 
Table 1. The location of T. arctica populations and sample size of surveyed populations in South Korea $(N$ = sample size $)$

\begin{tabular}{c|c|c|c|c|c|c}
\hline No. & Population & Latitude & Longitude & $\begin{array}{c}\text { Altitude } \\
(\mathbf{m})\end{array}$ & $\begin{array}{c}\text { Slope } \\
\text { orientation }\end{array}$ & N \\
\hline 1 & Yong-neup (YN) & $38^{\circ} 12^{\prime} 46.4^{\prime \prime}$ & $128^{\circ} 07^{\prime} 34.4^{\prime \prime}$ & 1,186 & - & 30 \\
2 & Mt. Seolark (SA1) & $38^{\circ} 08^{\prime} 08.4^{\prime \prime}$ & $128^{\circ} 20^{\prime} 07.6^{\prime \prime}$ & 1,206 & $\mathrm{NE}$ & 30 \\
3 & Mt. Seolark (SA2) & $38^{\circ} 07^{\prime} 14.6^{\prime \prime}$ & $128^{\circ} 23^{\prime} 23.3^{\prime \prime}$ & 1,477 & $\mathrm{~N}$ & 30 \\
4 & Mt. Seolark (SA3) & $38^{\circ} 07^{\prime} 05.0^{\prime \prime}$ & $128^{\circ} 27^{\prime} 50.3^{\prime \prime}$ & 1,597 & $\mathrm{NE}$ & 30 \\
5 & Mt. Taebaek (TB1) & $37^{\circ} 06^{\prime} 23.6^{\prime \prime}$ & $128^{\circ} 54^{\prime} 38.9^{\prime \prime}$ & 1,276 & $\mathrm{NW}$ & 30 \\
6 & Mt. Taebaek (TB2) & $37^{\circ} 05^{\prime} 29.8^{\prime \prime}$ & $128^{\circ} 56^{\prime} 31.3^{\prime \prime}$ & 15,12 & $\mathrm{NW}$ & 30 \\
7 & Mt. Gaya (GY) & $35^{\circ} 49^{\prime} 11.1^{\prime \prime}$ & $128^{\circ} 07^{\prime} 27.6^{\prime \prime}$ & 1,425 & $\mathrm{NE}$ & 30 \\
8 & Mt. Jiri (JR1) & $35^{\circ} 20^{\prime} 52.9^{\prime \prime}$ & $127^{\circ} 44^{\prime} 93.3^{\prime \prime}$ & 1,586 & $\mathrm{NW}$ & 30 \\
9 & Mt. Jiri (JR2) & $35^{\circ} 18^{\prime} 05.5^{\prime \prime}$ & $127^{\circ} 41^{\prime} 18.7^{\prime \prime}$ & 1,600 & $\mathrm{NW}$ & 30 \\
\hline
\end{tabular}

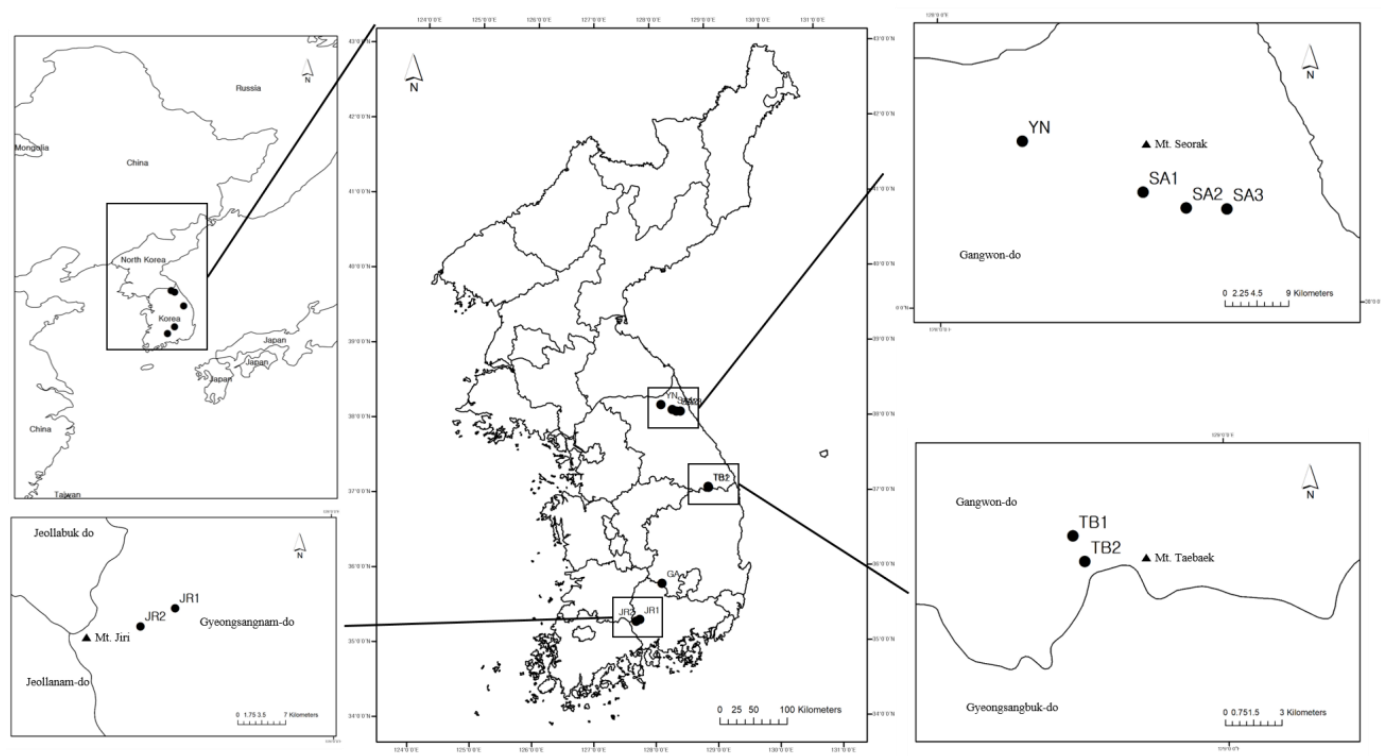

Figure 2. Geographical distribution of T. arctica populatons in Korea (Population abbreviations are shown in Table 1.)

\section{DNA extraction and RAPD polymerase chain reaction (PCR)}

Genomic DNA was extracted using the DNeasy® Plant mini kit (Qiagen Inc., Alameda, CA, USA). Leaf samples were frozen with liquid nitrogen and ground using a mortar and pestle. These ground samples were subjected to DNA extraction according to the manufacturer's instructions. The extracted DNA was diluted to a concentration of $25 \mathrm{ng} / \mu \mathrm{L}$ for RAPD PCR.

Ten random decamer primers from the A, N, O, P, and AF series were selected through screening (Qiagen Inc., Alameda, CA, USA) for RAPD analysis. Screening of the primers was performed in duplicate using two representatives from each of the nine populations and relied on the clarity and repeatability of the RAPD amplification bands.

We conducted RAPD amplification with a reaction volume of $20 \mu \mathrm{L}$, which contained $2.0 \mu \mathrm{L}$ of 10X PCR buffer, $1 \mathrm{U}$ Taq DNA polymerase (Takara Bio Inc., Shiga, Japan), $2.0 \mu \mathrm{L}$ of primer $(20 \mathrm{pmol})$, and $1.0 \mu \mathrm{L}$ of deoxyribonucleotide triphosphate (dNTP) 
mixture (2.5 mM each). We performed PCR in the TProfessional basic thermocycler (Biometra, Göttingen, Germany) with initial denaturation at $94{ }^{\circ} \mathrm{C}$ for $2 \mathrm{~min}$, followed by 36 cycles of $30 \mathrm{~s}$ at $94{ }^{\circ} \mathrm{C}$ (denaturation), $30 \mathrm{~s}$ at $36^{\circ} \mathrm{C}$ (annealing), and $1 \mathrm{~min}$ at $72{ }^{\circ} \mathrm{C}$ (extension), and a final extension at $72{ }^{\circ} \mathrm{C}$ for $10 \mathrm{~min}$. The PCR products were fractionated on $1.4 \%$ agarose gel in $0.5 \times$ tris-acetate-ethylenediaminetetraacetic acid (TAE) buffer for $30 \mathrm{~min}$. After electrophoresis, gels were stained with ethidium bromide and viewed and photographed under a UV transilluminator using the Gel Doc 2000 (BioRad Laboratories Inc., CA, USA) gel imaging system.

\section{Data analysis}

The binary data matrix was created by scoring the PCR-amplified band as " 1 ," if present, or " 0 ," if absent, for calculating the statistics of genetic variation. The data matrix was analyzed using POPGENE version 1.32 (Yeh et al., 1999) as follows: percentage of polymorphic bands (PPB), Nei's gene diversity $(H)$, Shannon information index $(I)$, observed number of alleles $(A o)$, effective number of alleles $(A e)$, coefficient of gene differentiation (Gst), and Nei's unbiased genetic identity and genetic distance.

To describe the partitioning of the genetic variance within and between populations, an analysis of molecular variance (AMOVA) was conducted using ARLEQUIN ver. 3.0 (Excoffier et al., 2005). The $\Phi$ statistics calculated from AMOVA and their significance were tested by 1000 permutations. The level of gene flow $(\mathrm{Nm})$, which is the proportion of new immigrant genes moving into a population, was calculated from the $\Phi_{s t}$ using the formula: $\mathrm{Nm}=1 / 4\left(1-\Phi_{s t}\right) / \Phi_{s t}$ (Slatkin and Barton, 1989). The relationships between the populations were displayed as a dendrogram through an unweighted pair-group method with arithmetic average (UPGMA) clustering method using POPGENE 1.32.

A principal coordinate analysis ( $\mathrm{PCoA}$ ) was carried out by plotting Euclidean distance in three-dimensional space, which was calculated on the basis of an RAPD binary matrix, to determine how individuals from all populations clustered together by using GenAlEx 6.5 (Peakall and Smouse, 2006) The correlation between geographic distance $(\mathrm{km})$ and genetic distance among populations was calculated using the Mantel test (Mantel, 1967) and GenAlEx 6.5.

\section{Results}

\section{Genetic diversity}

The ten selected RAPD primers yielded 81 reliable bands across 270 individuals from nine $T$. arctica populations. The average number of bands and polymorphic bands per primer were 8.1 and 7 , respectively (Table 2). The genetic variation parameters of the T. arctica populations based on RAPD markers are summarized in Table 3.

The genetic diversity indices of $T$. arctica were significantly higher at the species level than at the population level. The PPB was $86.4 \%$ at the species level but ranged from $18.52 \%$ to $1.26 \%$ at the population level, and the population mean was $7.1 \%$. The Ao value was 1.864 at the species level, ranged from 1.185 to 1.012 at the population level, and the population mean was 1.071. The Ae value was 1.454 at the species level, ranged from 1.105 to 1.007 at the population level, and the population mean was 1.039 . The $H$ value was 0.271 at the species level, ranging from 0.065 to 0.005 at the population level, and the population mean was 0.024 . The $I$ value was 0.412 at the species level, ranging from 0.008 to 0.099 at the population level, and the population mean was 0.036 . 
Table 2. Random amplification polymorphic DNA (RAPD) primer sequences and amplified products for nine T. arctica populations in South Korea

\begin{tabular}{c|c|c|c}
\hline Primer & Sequence (3'-5') & No. of loci & No. of polymorphic loci \\
\hline OPA-10 & GTGATCGCAG & 7 & 5 \\
OPN-08 & ACCTCAGCTC & 6 & 6 \\
OPN-11 & TCGCCGCAAA & 10 & 8 \\
OPN-15 & CAGCGACTGT & 9 & 8 \\
OPO-03 & CTGTTGCTAC & 8 & 8 \\
OPP-05 & CCCCGGTAAC & 7 & 7 \\
OPP-06 & GTGGGCTGAC & 7 & 5 \\
OPAF-11 & ACTGGGCCTC & 8 & 6 \\
OPAF-16 & TCCCGGTGAG & 10 & 10 \\
OPAF-17 & TGAACCGAGG & 9 & 7 \\
Mean & & 8.1 & 7 \\
\hline
\end{tabular}

Table 3. The genetic variations revealed through random amplification polymorphic DNA $(R A P D)$ markers among populations of T. arctica in South Korea

\begin{tabular}{c|c|c|c|c|c}
\hline Populations & PPB & $\boldsymbol{A o}$ & $\boldsymbol{A} \boldsymbol{e}$ & $\boldsymbol{H}$ & $\boldsymbol{I}$ \\
\hline YN & 2.5 & 1.024 & 1.017 & 0.010 & 0.015 \\
SA1 & 1.2 & 1.012 & 1.011 & 0.006 & 0.008 \\
SA2 & 4.9 & 1.049 & 1.016 & 0.012 & 0.019 \\
SA3 & 9.9 & 1.099 & 1.049 & 0.032 & 0.050 \\
TB1 & 18.5 & 1.185 & 1.105 & 0.065 & 0.099 \\
TB2 & 3.7 & 1.037 & 1.007 & 0.005 & 0.009 \\
GY & 14.8 & 1.148 & 1.084 & 0.051 & 0.077 \\
JR1 & 3.7 & 1.037 & 1.027 & 0.016 & 0.023 \\
JR2 & 4.9 & 1.049 & 1.031 & 0.018 & 0.028 \\
Average & 7.1 & 1.071 & 1.039 & 0.024 & 0.036 \\
Total & 86.4 & 1.864 & 1.454 & 0.271 & 0.412 \\
\hline
\end{tabular}

$\mathrm{PPB}=$ Percentage of polymorphic band; $\mathrm{Ao}=$ Observed number of alleles; Ae= Effective number of alleles; H=Nei's gene diversity; I=Shannon's information index; Population abbreviations are shown in Table 1

Among the nine populations, the population with the highest genetic diversity was the TB1 population, followed by the GY and SA3 populations. In comparison with the other populations, the SA1 population had the lowest genetic diversity in the PPB, Ao, Ae, and $I$ indices, and the TB2 population in the $H$ index. The genetic diversity of each population differed even for subpopulations distributed on the same mountain. In particular, the Mt. Taebaek subpopulations showed large differences in their genetic diversity.

\section{Genetic structure}

The coefficient of genetic differentiation between populations, derived from Nei's genetic diversity statistics, showed a significantly high value $(G s t=0.911)$. This indicates that each population is highly differentiated with a large genetic difference, similar to the results obtained from the AMOVA analysis. According to our AMOVA analysis, $96 \%$ of the total genetic variation was due to genetic differences between populations, and only the remaining $4 \%$ was due to variations within populations (Table 4). These results show that individuals within a population are nearly genetically homogeneous, while genetic differences between populations are quite large. This is also supported by the results of 
the PCoA analysis, which showed that each individual in a population was distributed independent from individuals in other populations to form their own populations (Fig. 3).

Table 4. Analysis of molecular variance (AMOVA) for populations of T. arctica in South Korea

\begin{tabular}{c|c|c|c|c}
\hline Source of variance & d.f. & Variance components & \% of total variance & $P$-value \\
\hline Among Populations & 8 & $2,760.489$ & 96 & $<0.001$ \\
Within Population & 261 & 109.467 & 4 & \\
Total & 269 & $2,869.956$ & 100 & \\
\hline
\end{tabular}

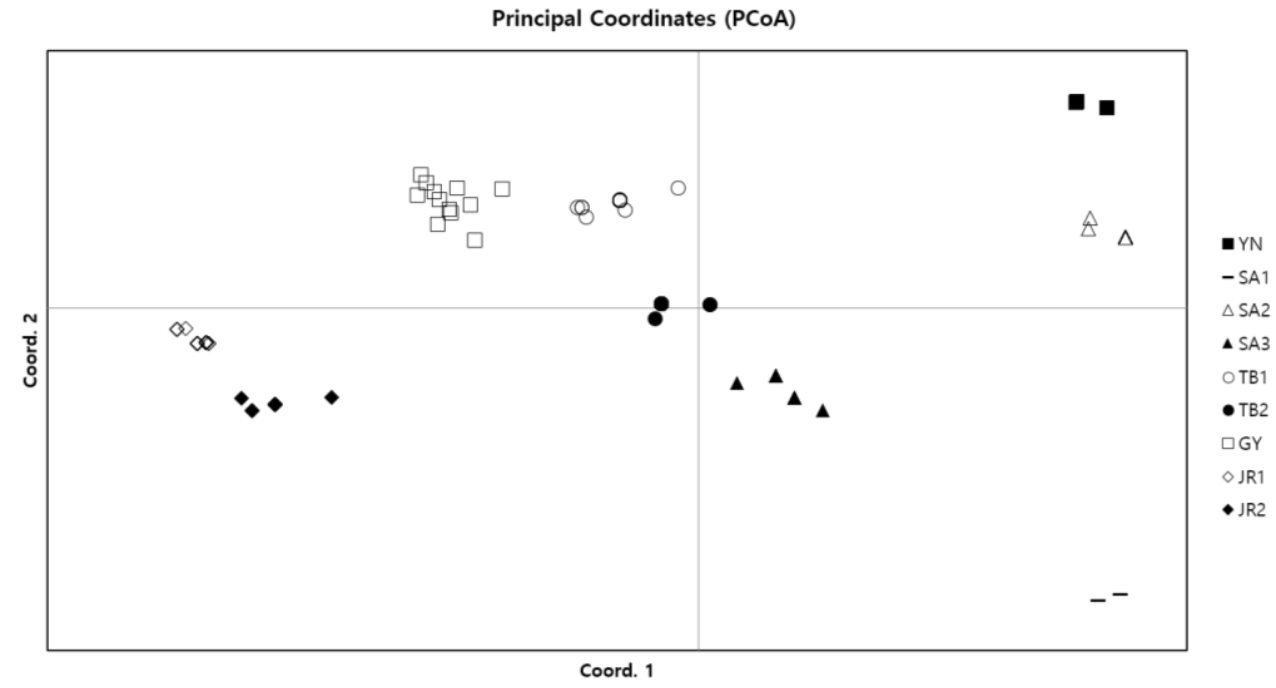

Figure 3. Principal coordinates analysis (PCoA) plot for 270 individuals from nine T. arctica populations in South Korea based on Random Amplification Polymorphic DNA (RAPD) markers. Population abbreviations are shown in Table 1

Genetic distances between individual populations ranged from 0.173 to 0.515 , with significant differences between pairs of populations (Table 5). The genetic distance was the shortest between the two sub-populations on Mt. Taebaek, and the genetic distance between SA1 and JR1 was the farthest. Our results showed that SA3 and SA2, which are subpopulations on Mt. Seorak, showed relatively close genetic distance, but SA1 showed the greatest genetic distance from other populations.

Table 5. Genetic identities (above diagonal) and Nei's genetic distance (below diagonal) between nine populations of $T$. arctica in South Korea

\begin{tabular}{c|c|c|c|c|c|c|c|c|c}
\hline Population & YN & SA1 & SA2 & SA3 & TB1 & TB2 & GY & JR1 & JR2 \\
\hline YN & - & 0.656 & 0.793 & 0.703 & 0.680 & 0.651 & 0.694 & 0.606 & 0.615 \\
SA1 & 0.422 & - & 0.725 & 0.733 & 0.633 & 0.686 & 0.630 & 0.598 & 0.609 \\
SA2 & 0.232 & 0.322 & - & 0.828 & 0.772 & 0.752 & 0.715 & 0.630 & 0.632 \\
SA3 & 0.352 & 0.311 & 0.189 & - & 0.760 & 0.791 & 0.736 & 0.744 & 0.763 \\
TB1 & 0.386 & 0.458 & 0.259 & 0.274 & - & 0.841 & 0.800 & 0.719 & 0.730 \\
TB2 & 0.430 & 0.378 & 0.285 & 0.235 & 0.173 & - & 0.758 & 0.725 & 0.715 \\
GY & 0.366 & 0.462 & 0.335 & 0.306 & 0.224 & 0.278 & - & 0.824 & 0.728 \\
JR1 & 0.501 & 0.515 & 0.461 & 0.296 & 0.329 & 0.322 & 0.194 & - & 0.805 \\
JR2 & 0.486 & 0.497 & 0.459 & 0.271 & 0.315 & 0.336 & 0.318 & 0.217 & - \\
\hline
\end{tabular}

Population abbreviations are shown in Table 1 
The UPGMA dendrogram, which was constructed based on the genetic distance between each population, showed that populations were clustered according to geographic location with some exceptions (Fig. 4). The TB1 and TB2 populations were collected first, followed by SA2. Unlike the other two subpopulations on Mt. Seorak, SA1 showed the most distant relationship with all other populations. The YN population was the second-most distant, after SA1, from the rest of the populations. The two subpopulations of Mt. Jiri were not clustered closest to each other, but the JR1 and GY populations were collected first, after which the JR2 population was grouped.

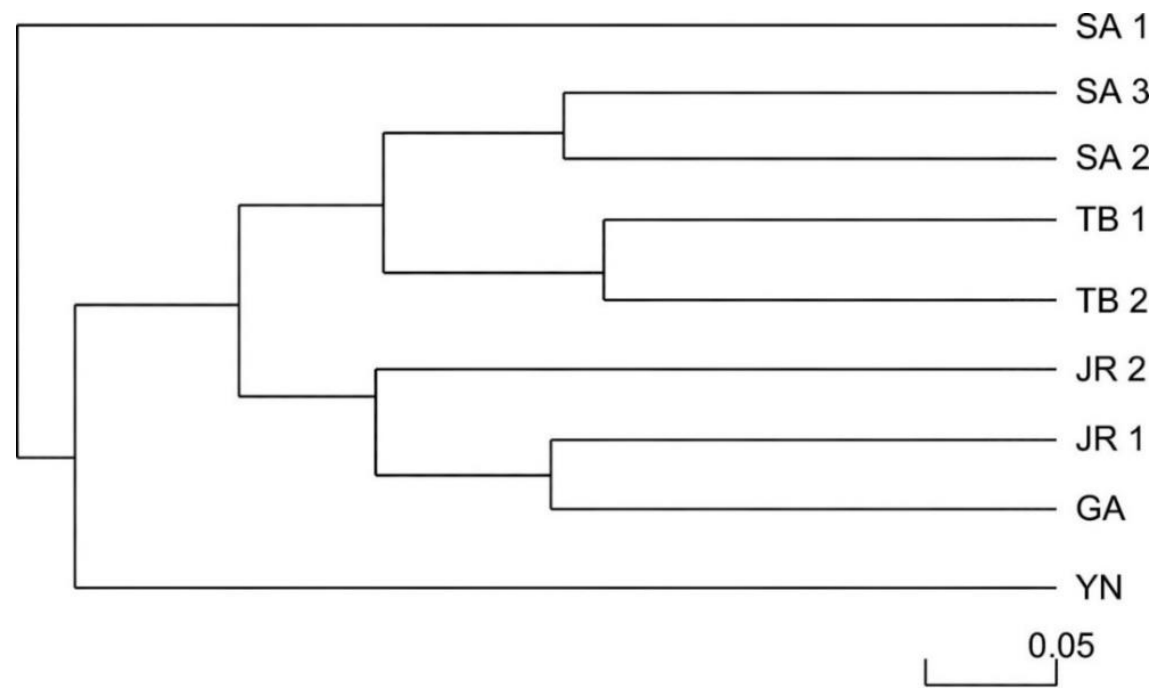

Figure 4. The unweighted pair group method with arithmetic mean (UPGMA) dendrogram of the nine T. arctica populations in South Korea. The scale bar represents Nei's genetic distance. Population abbreviations are shown in Table 1

The PCoA plot of the RAPD banding pattern of all T. arctica individuals showed that most individuals from a given population were inclined to cluster together (Fig. 3). Axis one and axis two explained $26.05 \%$ and $16.33 \%$ of the total genetic variation, respectively. The Mantel test showed no significant correlation between genetic and geographic distance $\left(r^{2}=0.03, p>0.090\right)$.

\section{Discussion}

\section{Genetic diversity}

T. arctica showed relatively high genetic diversity at the species level, but very low values at the population level. The genetic diversity at the species level was either higher or similar to that of other species of the same primula family (PPB $=86.4 \%, \mathrm{He}=0.27$, $\mathrm{I}=0.41)$. However, the genetic diversity at the population level was lower than that other species (Table 6).

The high genetic diversity of $T$. arctica at the species level is likely influenced by past ancestral populations. The distribution of many existing plant species is known to be influenced by the quaternary glaciers (Hewitt, 2000). Northern plants expanded to the south during the ice age, retreated to the north after the Interglacial Period, and were trapped in the low-temperature highlands. T. arctica, which is a northern plant, is also 
believed to have undergone the same process. Considering the worldwide distribution of $T$. arctica, the genetic variation of $T$. arctica distributed throughout the Korean Peninsula during the ice age may have been abundant. Therefore, the high species-level genetic diversity at present is thought to have been inherited from the high genetic diversity of the ancestral populations (Comes and Kaderetit, 1998; Ge et al., 2005).

Table 6. Comparison of the genetic diversity in T. arctica and literature data for other Primulaceae species

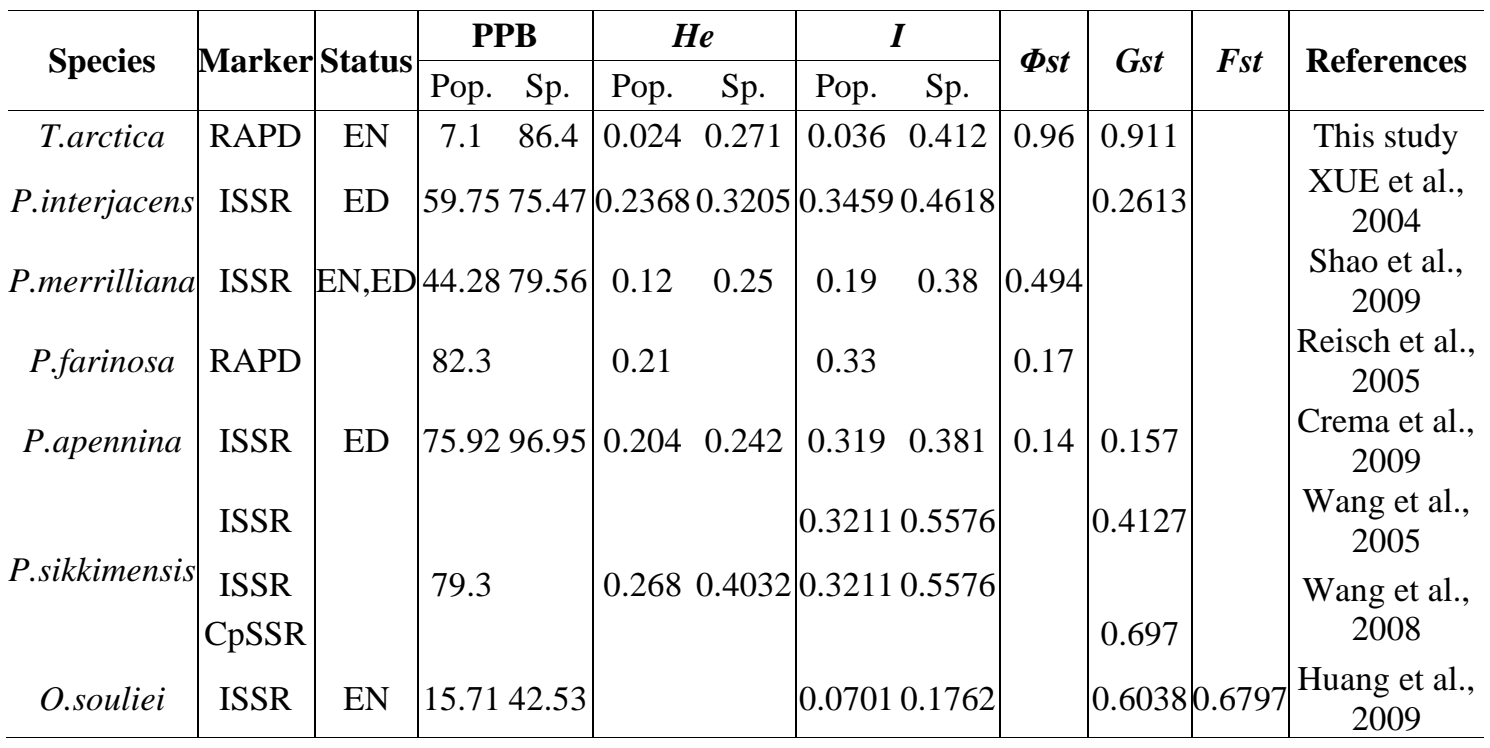

EN $=$ Endangered species; ED $=$ Endemic species $; \mathrm{PPB}=$ Percentage of Polymorphic Band; $\mathrm{He}=$ Expected Heterozygosity; I = Shannon's information index; Pop. = Population level; Sp. = Species level; RAPD =Rrandom Amplification Polymorphic DNA; ISSR = Inter Simple Sequence Repeat; CpSSR = Chloroplast Simple Sequence Repeat

At the population level, T. arctica showed low genetic diversity (Table 6). The genetic diversity of any species or population is a product of the combined effects of genealogical history and evolutionary processes (Comes and Kaderetit, 1998). The low genetic diversity of $T$. arctica at the population level can be explained by two causes: historical factors and the life history of T. arctica. First, the diversity of the T. arctica population was very low in comparison with the diversities of populations with similar life-history traits. It was lower than the average of perennial herbs and lower than those of selffertilizing plants and clonal plants (Nybom, 2004). It was also lower than that of other Primulaceae species (Table 6). The main reason for the low population-level genetic diversity may have been the historical factors associated with this species. Long-term isolation and a reduction in population size may cause multiple genetic drifts, resulting in the loss of genetic variation and a decrease in genetic diversity within the population. Second, the low population-level genetic diversity of $T$. arctica is affected by the life history of T. arctica, which is known to reproduce primarily by its creeping roots in the ground (Tylor et al., 2002). These reproductive methods are advantageous in maintaining the survival of individuals but may be disadvantageous in terms of genetic diversity. When populations are divided or suffer local extinctions due to various reasons such as fire, feeding, and extreme weather, clonal plants have an advantage in increasing the number of individuals but, since all daughters have the same genotype, their genetic 
diversity decreases. Therefore, the low genetic diversity of $T$. arctica at the population level is due to the fact that the current population consists of individuals originating from a small number of individuals.

\section{Genetic differentiation and gene flow among populations}

The genetic structure of a plant population reflects the interaction of various factors such as long-term evolutionary history, genetic drift, mating system, gene flow, and selection (Hamrick and Godt, 1996; Nybom and Bartish, 2000; Nybom, 2004). The AMOVA analysis was performed to measure the degree of genetic differentiation among T. arctica populations, and it showed an $\Phi$ st value of 0.96 , indicating a very high level of inter-population genetic differentiation. This means that $96 \%$ of the total genetic variation is attributable to the genetic difference between populations and only the remaining $4 \%$ is due to the genetic variation within populations. In addition, $\mathrm{Nm}$, which was calculated on the basis of the $\Phi_{s t}$ value, showed a very low value of 0.01 , indicating only 0.01 individuals between populations per generation move. Thus, each $T$. arctica population is composed of a small number of genetic traits that are very different from each other, and there is no exchange of genetic traits between them. These results showed a similar trend as that from the Gst value derived from Nei's genetic statistics, which was 0.911 . In comparison, in studies using dominant markers RAPD and ISSR for other constituents of the same family, Primula farinose, Primula interjacens, Primula merrilliana, Primula apennina, and Primula sikkimensis had $\Phi_{\text {st }}$ or Gst values ranging from 0.14 to 0.49 . The $G s t$ value of $T$. artica in our study was very high in comparison with these values. In addition, Omphalogramma souliei showed a $\Phi_{s t}$ value of 0.60 and an Fst value of 0.68 , which was relatively high but lower than that of T. arctica (Table 6). A previous study by Nybom (2004), which summarizes the genetic variation indices reported in RAPD studies, shows that the genetic differentiation of plant species with life history traits such as annual life form $\left(\Phi_{S t}=0.62, G s t=0.47\right)$, selfing breeding system $\left(\Phi_{s t}=0.65\right.$, $G s t=0.59)$, and attached seed dispersal mechanism $(\Phi s t=0.46, G s t=0.32)$ is higher than that of other forms. T. arctica showed significantly higher values $\left(\Phi_{s t}=0.96\right.$, $G s t=0.911)$ than these values, regardless of the corresponding life history traits. T. arctica shows an extremely high degree of genetic differentiation, and the main reason for this phenomenon is probably the low genetic diversity of populations as well as the decline in habitats due to climate change and long-term isolation of this species. This may be due to the historical process.

The genetic differentiation analysis suggested that $T$. arctica populations were very different from each other and were genetically independent, and PCoA analysis also showed that this trend was consistent. Individuals from individual populations did not mix with individuals from other populations, and there was no significant relationship among populations. The UPGMA dendrogram showed a form in which the geographic location and genetic distance did not completely match. Each subpopulation generally showed close correlation with each other, but there were also very heterogeneous populations, such as SA1. In addition, the Mantel test showed low significance and no correlation between geographic distance and genetic distance $\left(r^{2}=0.03, p>0.09\right)$. This is thought to be the result of genetic diversity within the population, even though the populations are geographically close and the gene flow between populations is very low $(N m=0.01)$. The loss of common genotypes between populations is caused by a variety of reasons, such as habitat fractionation and genetic drift, whereas the fixation of 
population-specific traits is thought to increase genetic differences between populations because genetic commonality cannot be restored due to low gene flow.

\section{Implications for conservation}

Maintenance of genetic variation is one of the main objectives of conservation of endangered and threatened species, and knowledge of genetic variation within and between populations provides essential information for the proper conservation management (Hamrick and Godt, 1996). The results of this study show that the T. arctica population has low genetic diversity, high genetic differentiation, and very low gene flow. This information could be applied for conservation of T. arctica.

Since each population of $T$. arctica has low genetic diversity and exhibits an independent genetic trait, all populations should be subject to in situ conservation. Specific management options for in situ conservation should take into account the habitat and physiological and ecological characteristics of this species. First, the area where each population is located must be designated as a conservation area and protected, and the conservation of woody vegetation in the upper layer is necessary depending on the characteristics of species located in the herbaceous layer of forest vegetation. Since a large number of populations are located around the trails, damage caused by foot pressure by implementation of facilities such as fences or changes to the trails should be minimized. In addition, damage or loss of the soil around the habitat should be taken into account, considering the life history of the species, which breeds mainly by generating bulbs under the ground.

Considering the characteristics of species with high genetic differentiation, the collection of germplasms for ex situ conservation should be carried out in the maximum possible number of populations so as to allow segregation of as many genetic traits as possible. Since the level of genetic variation of the selectively neutral marker loci is mainly generated by mutation or genetic drift (Kimura, 2020), the level of variation detected by RAPD does not directly reflect the level of variation that determines the degree of adaptation or the individual's fitness (Booy et al., 2000). Therefore, samples from various habitats should be considered for conservation (Ge et al., 2005). When considering the restoration of habitats or the creation of alternative habitats, it is necessary to select an area with the ecological characteristics of the species habitats, such as relatively low temperatures (average temperature in July, below $15.6^{\circ} \mathrm{C}$ ), high organic matter content in the soil, and relatively low soil pH (Taylor et al., 2002). For conservation of botanical or genetic resources, the genetic diversity of the population should be increased by introducing individuals from various populations, considering the low genetic diversity of a single population.

A representative example of successful conservation and restoration of alpine plants is Potentilla robbinsiana in Illinois, USA. Habitat protection through the relocation of hiking trails and designation of protected areas, long-term monitoring, and various research and restoration work on the habitats ensured the development of stable populations and eventually removing them from list of endangered species (Brumback et al., 2004). The case of this species may help the research and management groups in the protection and restoration of $T$. arctica. 


\section{Conclusions}

The aim was to study attempted to determine the level and structure of genetic variation in nine natural populations of T. arctica, an endangered species in South Korea, by using RAPD markers. In South Korea, these results were studied here first in natural populations of $T$. arctica.

T. arctica has high genetic diversity at the species level, but low genetic diversity at the population level. In addition, $T$. arctica showed a high degree of genetic differentiation between populations and limited gene flow. The genetic diversity and structure of $T$. arctica are thought to be influenced by the historical factor as an ice age species and life history traits, which are clonal plants.

Considering the genetic diversity and structure of this species, extremely low genetic diversity in population level and high genetic differentiation, both in situ and ex situ conservation should be carried out actively for this species.

Further studies using various markers, such as allozyme amplified fragment length polymorphism (AFLP), and chloroplast DNA (cpDNA) sequences may help to obtain more accurate information on the level and structure of genetic variation in the T. arctica population. Moreover, comparison with the samples derived from other regions of the Northern Hemisphere, such as Europe or northern China, is expected to broaden the perspectives on the genetic linkage and current status of $T$. arctica population in South Korea.

Acknowledgement. This research was supported by the Chung-Ang University Research Scholarship Grants in 2021.

\section{REFERENCES}

[1] Booy, G., Hendriks, R. J. J., Smulders, M. J. M., Van Groenendael, J. M., Vosman, B. (2000): Genetic diversity and the survival of populations. - Plant biology 2(4): 379-395.

[2] Brumback,W. E., Weihrauch, D. M., Kimball, K. D. (2004): Propagation and Transplanting of an Endangered Alpine Species, Robbins' Cinquefoil Potentilla robbinsiana (Rosaceae). - Native Plants Journal 5(1): 91-97.

[3] Chung, M. Y., López-Pujol, J., Maki, M., Kim, K. J., Chung, J. M., Sun, B. Y., Chung, M. G. (2012): Genetic diversity in the common terrestrial orchid Oreorchis patens and its rare congener Oreorchis coreana: inference of species evolutionary history and implications for conservation. - Journal of Heredity 103: 692-702.

[4] Chung, M. Y., Moon, M. O., López-Pujol, J., Chung, J. M., Chung, M. G. (2013): Genetic diversity in the two endangered endemic species Kirengeshoma koreana (Hydrangeaceae) and Parasenecio pseudotaimingasa (Asteraceae) from Korea: Insights into population history and implications for conservation. - Biochemical Systematics and Ecology 51: 6069.

[5] Chung, M. Y., López-Pujol, J., Chung, M. G. (2014): Genetic homogeneity between Korean and Japanese populations of the broad-leaved evergreen tree Machilus thunbergii (Lauraceae): A massive post-glacial immigration through the Korean Strait or smoething else? - Biochemical Systematics and Ecology 53: 20-28.

[6] Comes, H. P., Kadereit, J. W. (1998): The effect of Quaternary climatic changes on plant distribution and evolution. - Trends in plant science 3: 432-438.

[7] Crema, S., Cristofolini, G., Rossi, M., Conte, L. (2009): High genetic diversity detected in the endemic Primula apennina Widmer (Primulaceae) using ISSR fingerprinting. - Plant Systematics and Evolution 280: 29-36. 
[8] Excoffier, L., Laval, G., Schneider, S. (2005): Arlequin (version 3.0): an integrated software package for population genetics data analysis. - Evolutionary Bioinformatics 1: 47-50.

[9] Ge, X. J., Zhang, L. B., Yuan, Y. M., Hao, G., Chiang, T. Y. (2005): Strong genetic differentiation of the East-Himalayan Megacodon stylophorus (Gentianaceae) detected by inter-simple sequence repeats (ISSR). - Biodiversity \& Conservation 14(4): 849-861.

[10] Hamrick, J. L., Godt, M. J. W. (1996): Effects of life history traits on genetic diversity in plant species. - Philosophical Transactions of the Royal Society in Lodon, Series B 351: 1291-1298.

[11] Hewitt, G. (2000): The genetic legacy of the Quaternary ice ages. - Nature 405: 907-913.

[12] Hiirsalmi, H. (1969): Trientalis europaea L. A study of the reproductive biology, ecology and variation in Finland. - Annales Botanici Fennici 6: 119-173.

[13] Huang, Y., Zhang, C. Q., Li, D. Z. (2009): Low genetic diversity and high genetic differentiation in the critically endangered Omphalogramma souliei (Primulaceae): implications for its conservation. - Journal of Systematics and Evolution 47: 103-109.

[14] Jeong, J. H., Kim, E. H., Guo, W., Yoo, K. O., Jo, D. G., Kim, Z. S. (2010): Genetic diversity and structure of the endangered species Megaleranthis saniculifolia in Korea as revealed by allozyme and ISSR markers. - Plant systematics and evolution 289(1-2): 6776.

[15] Jiménez, J. F., Sánchez-Gómez, P., Güemes, J., Werner, O., Rosselló, J. A. (2002): Genetic variability in a narrow endemic snapdragon (Antirrhinum subbaeticum, Scrophulariaceae) using RAPD markers. - Heredity 89: 387-393.

[16] Kim, B. D., Kang, S. G., Yu, S. T., Shin, H. T. (2012): A study on the plants for phenology of the Mt. Gaya National Park. - Journal of Climate Research 7: 174-186.

[17] Kim, Y. C., Chae, H. H., Oh, S. H., Choi, S. H., Hong, M. P., Nam, G. H., Choi, J. Y., Choi, H. S., Lee, K. S. (2015): Floristic characteristics of vascular plants and first distributional report of Pseudostellaria baekdusanensis M. Kim in Yongneup wetland protected area. - Korean Journal of Environment and Ecology 29: 132-159.

[18] Kim, Y. Y., Leem, H., Han, S., Ji, S. J., So, S. (2017): Conservation measures and distribution of vulnerable species for climate change in Gayasan National Park. - Korean Journal of Plant Resources 30: 167-175.

[19] Kimura, M. (2020): The neutral theory and molecular evolution. In My Thoughts on Biological Evolution. - Springer, Singapore, pp 119-138.

[20] Korea National Arboretum. (2009): Rare plants data book in Korea. - GeoBook Publishing Co. Seoul.

[21] Kovanda, M. (1995): Reproductive strategy and morphological variation in Trientalis europea. - Verhandlungen der Zoologisch-Botanischen Gesellschaft in Österreich 132: 251-264.

[22] Lee, T. B. (2003): Illustrated Flora of Korea. - Hyang-mun Pub. Co., Seoul.

[23] Lee, Y. N. (2006): New flora of Korea. - Kyo-Hak Pub. Co., Seoul.

[24] Lee, S. H., Yeon, M. H., Shim, J. K. (2016): Conservation implications of the genetic diversity of Gymnospermium microrrhynchum in Korea. - Genetics and molecular research: GMR 15.4.

[25] Li, L., Park, E. K., Park, M. O., Koo, B. H. (2014): Ecosystem Analysis for Little Yongneup, Baby Yong-neup in Daeam-san in Korea. - Journal of the Korean Society of Environmental Restoration Technology 17: 43-56.

[26] Mantel, N. (1967): The detection of disease clustering and a generalized regression approach. - Cancer Research 27: 209-220.

[27] Nybom, H., Bartish, I. V. (2000): Effects of life history traits and sampling strategies on genetic diversity estimates obtained with RAPD markers in plants. - Perspectives in Plant Ecology, Evolution and Systematics 3(2): 93-114.

[28] Nybom, H. (2004): Comparison of different nuclear DNA markers for estimating intraspecific genetic diversity in plants. - Molecular ecology 13: 1143-1155. 
[29] Park, K. H., Son, J. I., Kwon, J. H. (2011): A Study on Vascular Plants around the SeobukRidgeline of Seoraksan National Park. - Journal of National Park Research 2: 19-32.

[30] Park, J. H., Kim, J. G. (2012): Ecological Characteristics of Pseudostellaria baekdusanensis in Mt. Odae: 2. Conservation Area of Jilmoe-neup. - Journal of Wetlands Researh 14: 101-120.

[31] Pauls, S. U., Nowak, C., Bálint, M., Pfenninger, M. (2013): The impact of global climate change on genetic diversity within populations and species. - Molecular Ecology 22: 925946.

[32] Peakall, R., Smouse, P. E. (2006): GENALEX 6 genetic analysis in Excel. Population genetic software for teaching and research. - Molecular Ecology Notes 6: 288-295.

[33] Piqueras, J., Klimes, L. (1998): Demography and modeling of clonal fragments in the pseudoannual plant Trientalis europea L. - Plant ecology 136: 213-227.

[34] Piqueras, J. (1999): Herbivory and ramet performance in the clonal herb Trientalis europeae L. - Journal of Ecology 87: 450-460.

[35] Piqueras, J., Klimes, L., Redbo-Torstensson, P. (1999): Modelling the morphological response to nutrient availability in the clonal plant Trientalis europaea L. - Plnat Ecology 141: 117-127.

[36] Reisch, C., Anke, A., Röhl, M. (2005): Molecular variation within and between ten populations of Primula farinosa (Primulaceae) along an altitudinal gradient in the northern Alps. - Basic and Applied Ecology 6: 35-45.

[37] Shao, J. W., Chen, W. L., Peng, Y. Q., Zhu, G. P., Zhang, X. P. (2009): Genetic diversity within and among populations of the endangered and endemic species Primula merrilliana in China. - Biochemical Systematics and Ecology 37: 699-706.

[38] Shin, H. T., Yi, M. H., Yoon, J. W., Yoo, J. H., Lee, B. C., Park, E. H. (2010): Distribution of rare plants and endemic plants in Jirisan national park. - Journal of Korean Nature 3: 219-222.

[39] Singh, S., Panda, M. K., Nayak, S. (2012): Evaluation of genetic diversity in turmeric (Curcuma longa L.) using RAPD and ISSR markers. - Industrial Crops and Products 37: 284-291.

[40] Slatkin, M., Barton, N. H. (1989): A comparison of three indirect methods for estimating average levels of gene flow. - Evolution 43: 1349-1368.

[41] Song, J. M., Choi, K. H., Lee, K. Y. (2009): Soil Properties and Vegetation Structure of Natural Habitat of Endangered Plant, Trientalis europaea L. - Journal of Korean Society of Forest Science Academic Symposium Annual Report, pp. 163-165.

[42] Sung, J. W., Kim, G. H. (2018): Changes of Flowering Time Affected by Climate Change in the Subalpine Region of Mt. Gaya. - Journal of Agriculture \& Life Science 52: 13-23.

[43] Taylor, K., Havill, D. C., Pearson, J., Woodall, J. (2002): Trientalis europaea L. - Journal of Ecology 90(2): 404-418.

[44] Tikhodeyev, O. N., Neustroeva, M. A., Tikhodeyeva, M. Y. (2003): (+1) and (-1) deviations in development of floral meristems in Trientalis europaea L. - Wulfenia 10: 103-114.

[45] Wang, F. Y., Ge, X. J., Hao, G., Hu, Q. M. (2005): Genetic diversity and differentiation in Primula sikkimensis (Primulaceae) in Himalayan-hengduan mountains. - Journal of Tropical and Subtropical Botany 13: 149-153.

[46] Wang, F. Y., Ge, X. J., Gong, X., Hu, C. M., Hao, G. (2008): Strong genetic differentiation of Primula sikkimensis in the East Himalaya-Hengduan Mountains. - Biochemical Genetics 46: 75-87.

[47] Wang, Y., Qin, Y., Du, Z., Yan, G. (2012): Genetic diversity and differentiation of the endangered tree Elaeagnus mollis Diels (Elaeagnus L.) as revealed by Simple Sequence Repeat (SSR) Markers. - Biochemical Systematics and Ecology 40: 25-33.

[48] Williams, J. G., Kubelik, A. R., Livak, K. J., Rafalski, J. A., Tingey, S. V. (1990): DNA polymorphisms amplified by arbitrary primers are useful as genetic markers. - Nucleic acids research 18: 6531-6535. 
[49] Xue, D. W., Ge, X. J., Hao, G., Zhang, C. Q. (2004): High genetic diversity in a rare, narrowly endemic primrose species: Primula interjacens by ISSR analysis. - Acta Botanica Sinica (English edition) 46: 1163-1169.

[50] Yeh, F. C., Boyle, T., Yang, R. C. (1999): PopGene. - Microsoft Window-based freeware for population genetic analysis, version 1.31 .

[51] Yoon, J. W., Shin, H. T., Kim, S. J., Heo, T. I., An, J. B., Kwon, Y. H. (2015): A Study on the Distribution of Rare and Endemic Plants in Eastern DMZ Region. - Korean Journal of Plant Resources Academic Symposium, p.27. 